\section{Should we be advising patients to take their antihypertensives at night?}

I have read with great interest a research paper entitled 'Bedtime hypertension treatment improves cardiovascular risk reduction: the Hygia Chronotherapy Trial' published in the European Heart Journal by Hermida et al. ${ }^{1}$

The trial randomly assigned 19084 patients to either take their antihypertensives upon waking in the morning or at bedtime. The patients were subsequently followed up over a median period of 6.3 years with ambulatory 48-hour blood pressure monitoring done at inclusion and at least annually.

After adjusting for significant confounding variables such as sex, age, smoking history, type 2 diabetes, chronic kidney disease, previous and cardiovascular events, among others, the risk of cardiovascular death, myocardial infarction, coronary revascularisation, heart failure, or stroke nearly halved (6.5\% vs. $11.9 \%$ ).

National Institute for Health and Care Excellence advice on starting antihypertensive drug treatment was last updated prior to the publication of this research and does not recommend a time of day to give the medication. ${ }^{2}$

With the results seeming almost too good to be true - the New England Journal of Medicine (NEJM) Journal Watch, a sibling publication to the NEJM, reviewed the article. They made the point that ideally the trial would be replicated; however, given the significant difference in adverse outcome with morning dosing, they questioned whether it would be ethically sound to randomise patients to the morning dosing arm. Ultimately, they felt recommending that patients take oncedaily antihypertensive drugs in the evening was reasonable. ${ }^{3}$

Nature Reviews Cardiology has also acknowledged that, while the mechanism is unclear, the time of dosing is important for blood pressure control and protection against cardiovascular disease. ${ }^{4}$

Given these findings, l'd encourage fellow clinicians to consider recommending patients to take their antihypertensives at night. The question is now whether future guidelines will take note of this trial and recommend night dosing of antihypertensives.
Gurjeevan Bal,

Senior House Officer, St George's

University Hospitals NHS Foundation Trust,

London.

Email: g.bal1anhs.net

Chan Song Kim,

Senior House Officer, Epsom and St Helier University Hospitals Foundation Trust, Epsom.

\section{REFERENCES}

1. Hermida RC, Crespo JJ, Domínguez-Sardiña $\mathrm{M}$, et al. Bedtime hypertension treatment improves cardiovascular risk reduction: the Hygia Chronotherapy Trial. Eur Heart J 2019; 41(48): 4565-4576.

2. National Institute for Health and Care Excellence. Treating and monitoring hypertension. In: Hypertension in adults: diagnosis and management. NG136. London: NICE, 2019. https://www.nice.org.uk/guidance/ng136/chapter/ recommendations\#treating-and-monitoringhypertension (accessed 7 Dec 2021).

3. Komaroff AL. Antihypertension medications might best be taken at night. NEJM Journal Watch 2019; https://www.jwatch.org/na50538/2019/12/26/ antihypertension-medications-might-best-betaken-night laccessed 7 Dec 2021).

4. Fernández-Ruiz I. Blood-pressure medication timing matters. Nat Rev Cardiol 2020; 17(1): 8.

DOI: https://doi.org/10.3399/bjgp22X718061

\section{Thus spoke Honda: philosophy and technology}

Euan Lawson' quoted the Japanese proverb Vision without action is a daydream. Action without vision is a nightmare.' These are the words of Soichiro Honda, the founder of the Honda Motor Company. He also wrote the following:

'Philosophy is more important than technologies. Things like money and technologies are merely the means to serve people. There is no meaning in a technology if, at the base of it, it does not consider people. What drives a firm's growth is philosophy. A true technology is a crystal of philosophy. Therefore, even in a research lab, the philosophy of the people who work there should take precedence over the technology. '2
In general practice, continuity and relationship are our cardinal philosophies, and the care we provide is a substitute for the technology. True care in general practice must be a crystal of our philosophies.

However, one of the obstacles to true care is the commercialisation of medicine. The key component of commercialisation is the reductionism of medical services. It increases the cost of medical services and erodes holistic concepts of health. ${ }^{3}$ The holistic concept, which has a root in the Hippocratic tradition, is central to general practice.

Yes. It is time to rewild general practice.

Koki Kato,

GP, Madoka Family Clinic; Academic \& Research Centre, Hokkaido Centre for Family Medicine, Japan.

Email: koki.katolahcfm.jp

\section{REFERENCES}

1. Lawson E. Rewilding, rebuilding, rebooting. $\mathrm{Br}$ J Gen Pract 2021; DOI: https://doi.org/10.3399/ bjgp21X717677.

2. Nonaka I, Toyama R. Strategic management as distributed practical wisdom (phronesis). Industrial and Corporate Change 2007; 16(3): 371-394. DOI: 10.1093/icc/dtm014

3. Churchill LR, Churchill, SC. Buying health: the costs of commercialism and an alternative philosophy. Int J Health Policy Manag 2013; 1(2): 91-93. DOI: 10.15171/ijhpm.2013.14.

DOI: https://doi.org/10.3399/bjgp22X718073 